\section{Kidney \\ Blood Pressure Research}

Kidney Blood Press Res 2019;44:52-61

DOI: 10.1159/000498834

Published online: 22 February 2019

Accepted: 5 February 2019

This article is licensed under the Creative Commons Attribution-NonCommercial-NoDerivatives 4.0 International License (CC BY-NC-ND) (http//www/karger.com/Services/OpenAccessLicense). Usage and distribution for commercial purposes as well as any distribution of modified material requires written permission.

\title{
Association Between the Lipid Profile and Renal Dysfunction in the Heart Failure Patients
}

\author{
Hong Zhang ${ }^{a}$ Shuang Shib Xiu-Juan Zhao ${ }^{c}$ Jun-Kui Wang ${ }^{b}$ \\ Zhong-Wei Liu ${ }^{b}$ Fu-Qiang Liu ${ }^{b} \quad$ Ling Zhub $^{b}$ Shun-Ming Zhu \\ Yong Zhang ${ }^{b}$ Shuo Pan ${ }^{b}$ \\ ${ }^{a}$ Department of Neurology, People's Hospital of Shaanxi Province, Xi'an, bFirst Department of \\ Cardiology, People's Hospital of Shaanxi Province, Xi'an, 'Department of Ultrasonic Center, Northwest \\ Women and Children's Hospital, Xi'an, China
}

\section{Key Words}

Lipid $• H D L-C \cdot$ Renal dysfunction $\cdot$ EGFR $\cdot$ Heart failure

\begin{abstract}
Background/Aims: In heart failure patients with high prevalence of chronic renal disease (CKD), hospitalization and mortality, whether the lipid profile was associated with renal dysfunction remained unknown. The present study intended to clarify the association between the lipid profile and renal dysfunction in the heart failure patients. Methods: 336 hospitalized heart failure patients with left ventricle ejection fraction (LVEF) $\leq 45 \%$ and New York Heart Association (NYHA) class II-IV were enrolled. The estimated glomerular filtration rate (eGFR) $<90 \mathrm{~mL} / \mathrm{min} \cdot 1.73 \mathrm{~m}^{2}$ was defined as renal dysfunction. The demographic, clinical data, blood samples and echocardiography were documented. The Pearson simple linear correlation was performed to evaluate the confounding factors correlated with eGFR. The significantly correlated factors were enrolled in Logistic regression as confounding factors to determine the association between the lipid profile and renal dysfunction in the heart failure patients. Results: 182 patients (54.2\%) had renal dysfunction and 154 patients (45.8\%) did not have renal dysfunction. The waist circumference, platelet counts, platelet distribution width (PDW), high density lipoprotein-cholesterol (HDL-C), apolipoprotein A1 (apoA1), albumin and left ventricular ejection fraction (LVEF) are positively correlated with eGFR (all $P<0.05$ ). Meanwhile, the age, mean platelet volume (MPV), neutrophilic granulocyte percentage (NEUT\%), urea nitrogen (BUN), creatinine and total bilirubin (TBIL) are negatively correlated with eGFR (all $P<0.05)$. The total cholesterol $(T C)$, triglyceride, low density lipoprotein-cholesterol (LDL-C) and apolipoprotein $B(a p o B)$ show no correlation with eGFR. After the adjustment of sex, hypertension, diabetes mellitus, age, waist circumference, platelet counts, MPV, PDW, NEUT\%,
\end{abstract}

H. Zhang, S. Shi, X-J. Zhao and J-K. Wang contributed equally to this work.

Yong Zhang M.D, Ph.D.

and Shuo Pan M.D, Ph.D.
First Department of Cardiology, People's Hospital of Shaanxi Province

Shaanxi, Xi'an 710068 (China)

Tel. +86 29 85251331, E-Mail parker1985@sina.com 


\section{Kidney Blood Pressure Research}

TBIL, albumin and LVEF, HDL-C is the only lipid factor still significantly associated with renal dysfunction in hospitalized heart failure patients $(O R=0.119, P=0.003)$. Conclusion: Among the lipid profile of TC, triglyceride, LDL-C, HDL-C, apo A1 and apo B, the HDL-C is the only lipid factor significantly associated with renal dysfunction in hospitalized heart failure patients.

(C) 2019 The Author(s)

Published by S. Karger AG, Basel

\section{Introduction}

Heart failure (HF) is often accompanied with renal dysfunction, and the relationship between heart and kidney has been discussed in a variety of studies [1-3]. Cole RT et al. [4] reviewed that $20 \%$ to $57 \%$ patients with chronic, stable $\mathrm{HF}$ and $30 \%$ to $67 \%$ patients with acutely decompensated HF had certain levels of renal dysfunction. According to a recent large sample UK study based on the 50,114 heart failure patients, the prevalence of CKD in the HF community was $63 \%$, it brought an $11 \%$ increase in hospitalization and $17 \%$ in mortality in heart failure patients [5]. The pathophysiological features have demonstrated that heart failure may cause the reduction in cardiac output and decrease in renal perfusion, which have became the primary driver for renal dysfunction in HF [6-8].

The shocking results have driven us to pay more attention to the renal dysfunction in heart failure patients, the associated risk factors should be intervened to decrease the prevalence, hospitalization and mortality. Among the various confounding factors for renal dysfunction in heart failure, the dyslipidemia has become an important element according to recent studies $[9,10]$. One recent study based on 188, 577 chronic kidney disease (CKD) patients (defined as estimated glomerular filtration rate (eGFR) $<60 \mathrm{~mL} / \mathrm{min} \cdot 1.73 \mathrm{~m}^{2}$ ) demonstrated that a $17-\mathrm{mg} / \mathrm{dL}$ increase in HDL cholesterol concentration was associated with a $0.8 \%$ increase in eGFR $(P=0.004)$ and lower risk for eGFR $<60 \mathrm{~mL} / \mathrm{min} \cdot 1.73 \mathrm{~m}^{2}$ $(O R=0.85, P<0.001)$ [11]. There was no evidence for a causal relationship between LDL cholesterol, triglyceride concentration and any kidney disease measure.

In heart failure patients with high CKD prevalence and also with high CKD induced hospitalization and mortality, whether the lipid profile was associated with renal dysfunction remained unknown. The present study intended to clarify the association between the lipid profile and renal dysfunction in the heart failure patients.

\section{Materials and Methods}

\section{Subjects}

We performed this present cross-sectional study in $1^{\text {st }}$ Cardiology Department of People's Hospital of Shaanxi Province from January 2017 to June in 2018. We enrolled hospitalized patients with left ventricular ejection fraction (LVEF) $\leq 45 \%$ and New York Heart Association (NYHA) class II-IV. NYHA class II is defined as mild symptoms (mild shortness of breath and/or angina) and slight limitation during ordinary activity. NYHA class III is defined as marked limitation in activity due to symptoms, even during less-than-ordinary activity, comfortable only at rest. NYHA class IV is defined as severe limitations in activity, even while at rest, who are mostly bedbound patients [12]. Heart failure was confirmed by clinical heart failure specialists and cardiologists after consulting with the symptoms and the echocardiography report. The main exclusion criteria included significant cognitive impairment, life-threatening comorbidity, and unwillingness for cooptation [13].

336 hospitalized patients with heart failure were enrolled, 188 patients (56.0\%) were male and 148 patients $(44.0 \%)$ were female. The patients were divided into two groups according to renal function, the renal dysfunction is defined as eGFR $<90 \mathrm{~mL} / \mathrm{min} \cdot 1.73 \mathrm{~m}^{2}$ [14]. 182 patients $(54.2 \%)$ had renal dysfunction and 154 patients $(45.8 \%)$ did not have renal dysfunction. 


\section{Kidney Blood Pressure Research}

Kidney Blood Press Res 2019;44:52-61
\begin{tabular}{l|l}
\hline DOl: 10.1159/000498834 & $\begin{array}{l}\text { c } 2019 \text { The Author(s). Published by S. Karger AG, Basel } \\
\text { www.karger.com/kbr }\end{array}$ \\
\hline Published onlIne: 22 February 2019
\end{tabular}

Zhang et al.: Lipid and Renal Dysfunction

eGFR calculation

eGFR is calculated using Modification of Diet in Renal Disease-Isotope Dilution Mass Spectrometry (MDRD-IDMS) equation, which is considered as the most appropriate calculation method in Chinese population [15].

\section{Demographic and clinical data}

Demographic data and cardiovascular risk factors were obtained from the medical records. Body weight was measured with a double balance placed on a firm surface while the shoes were taken off. Height was measured with a Frankfort plane positioned at a $90^{\circ}$ angle against a wall-mounted metal tape. The waist circumference was measured from the narrowest point between the lower borders of the rib cage and the iliac crest at the end of normal expiration and to the nearest $0.1 \mathrm{~cm} \mathrm{[16].}$

\section{Blood samples and echocardiography}

Peripheral blood was sampled from patients in a fasting state in the morning following the admission day. Venous blood samples were sent to Clinical Laboratory Department of People's Hospital of Shaanxi Province for red blood cells (RBC) counts, hemoglobin, platelet counts, plateletcrit, mean platelet volume (MPV), platelet distribution width (PDW), white blood cells (WBC) counts, neutrophilic granulocyte percentage (NEUT\%), total cholesterol (TC), triglyceride, high-density lipoprotein-cholesterol (HDL-C), low-density lipoprotein-cholesterol (LDL-C), apolipoprotein A1 (ApoA1), apolipoprotein B (ApoB), urea nitrogen (BUN), creatinine, total bilirubin (TBIL) and albumin detection using standard biochemical techniques. Echocardiographic data (left ventricular ejection fraction [LVEF]) was obtained using Doppler echocardiography conducted within 3 days of admission [17].

\section{Definition of risk factors}

Hypertension was defined as an average systolic blood pressure $\geq 140 \mathrm{~mm} \mathrm{Hg}$, or an average diastolic blood pressure $\geq 90 \mathrm{~mm} \mathrm{Hg}$, or both, or self-reported use of antihypertensive medication, or a self-reported history of hypertension.

Diabetes was defined as fasting plasma glucose $\geq 7.0 \mathrm{mmol} / \mathrm{L}$, or random plasma glucose $\geq 11.1 \mathrm{mmol} / \mathrm{L}$, or 2 hour plasma glucose in oral glucose tolerance test (OGTT) $\geq 11.1 \mathrm{mmol} / \mathrm{L}$, or use of insulin or oral hypoglycemic agents, or a self-reported history of diabetes.

Smoking index was defined as number of cigarettes smoked per day $\times$ years of smoking. Body mass index (BMI) was calculated as weight in $\mathrm{kg}$ divided by height in $\mathrm{m}^{2}$ [18].

\section{Statistical analysis}

The statistical analysis was conducted using SPSS version 16.0 for Windows (SPSS Inc., Chicago, IL, USA). Continuous variables were expressed as mean \pm standard deviations and the differences between the renal dysfunction group and the without renal dysfunction group were analyzed using the Mann-Whitney U-test. Categorical variables were expressed as proportions and the differences in categorical variables were analyzed using chi-square test and fisher exact test. Pearson correlation analysis was conducted to determine the correlation between eGFR and lipid and other clinical and laboratory factors. Logistic regression was performed to determine whether the lipids factors were associated with renal dysfunction after the adjustment of each confounding factor. Statistical significance was established at $P<0.05$.

\section{Results}

Baseline characteristics of heart failure patients with and without renal dysfunction are shown in Table 1. A total of 182 patients have renal dysfunction, counting for $54.2 \%$ of all 336 heart failure patients. The Mean \pm S.D. of eGFR is $66.14 \pm 16.01 \mathrm{~mL} / \mathrm{min} \cdot 1.73 \mathrm{~m}^{2}$ in patients with renal dysfunction and $120.68 \pm 22.20 \mathrm{~mL} / \mathrm{min} \cdot 1.73 \mathrm{~m}^{2}$ in patients without renal dysfunction. The percentage of women in patients with renal dysfunction is significantly higher than that in patients without renal dysfunction. 242 patients $(72.0 \%)$ have NYHA classification of class II, $70(20.8 \%)$ patients have NYHA classification of class III and 24 


\section{Kidney Blood Pressure Research}

Table 1. Baseline characteristics of heart failure patients with and without renal dysfunction. Note: NYHA, New York HeartAssociation; BMI, Body Mass Index; RBC, Red Blood Cells; MPV, Mean Platelet Volume; PDW, Platelet Distribution Width; WBC, White Blood Cells; NEUT\%, neutrophilic granulocyte percentage; TC, Total Cholesterol; HDL-C, High-Density Lipoprotein-Cholesterol; LDL-C, Low-Density LipoproteinCholesterol; apoA1, apolipoprotein A1; apoB, apolipoprotein B; BUN, Urea Nitrogen; eGFR, estimated glomerular filtration rate; TBIL, Total Bilirubin; LVEF, left ventricular ejection fraction; * $\mathrm{P}<0.05$

\begin{tabular}{|c|c|c|c|}
\hline Factors & With renal dysfunction $(n=182)$ & Without renal dysfunction $(n=154)$ & $P$ value \\
\hline Sex & & & $<0.001^{*}$ \\
\hline Men & $82(45.1 \%)$ & $106(68.8 \%)$ & \\
\hline Women & $100(54.9 \%)$ & $48(31.2 \%)$ & \\
\hline NYHA classification & & & $<0.001^{*}$ \\
\hline II & 108 (59.3\%) & $134(87.0 \%)$ & \\
\hline III & $52(28.6 \%)$ & $18(11.7 \%)$ & \\
\hline IV & $22(12.1 \%)$ & $2(1.3 \%)$ & \\
\hline Hypertension & $116(63.7 \%)$ & $78(50.6 \%)$ & $0.016^{*}$ \\
\hline Diabetes mellitus & $52(28.6 \%)$ & $26(16.9 \%)$ & $0.011^{*}$ \\
\hline Age (years) & $63.47 \pm 11.08$ & $60.96 \pm 10.16$ & $0.013^{*}$ \\
\hline BMI $\left(\mathrm{kg} / \mathrm{m}^{2}\right)$ & $23.66 \pm 3.49$ & $24.10 \pm 3.03$ & 0.205 \\
\hline Waist circumference $(\mathrm{cm})$ & $84.08 \pm 9.77$ & $86.98 \pm 9.16$ & $0.003^{*}$ \\
\hline Smoking index & $85.33 \pm 180.10$ & $98.96 \pm 218.92$ & 1.000 \\
\hline RBC counts $\left(\times 10^{12} / \mathrm{L}\right)$ & $4.31 \pm 0.58$ & $4.24 \pm 0.56$ & 0.095 \\
\hline Hemoglobin $(\mathrm{g} / \mathrm{L})$ & $134.08 \pm 17.79$ & $131.73 \pm 17.67$ & 0.220 \\
\hline Platelet counts $\left(\times 10^{9} / \mathrm{L}\right)$ & $184.15 \pm 49.39$ & $184.30 \pm 60.50$ & 0.748 \\
\hline Plateletcrit (\%) & $0.19 \pm 0.05$ & $0.18 \pm 0.05$ & $0.013^{*}$ \\
\hline MPV (fL) & $10.55 \pm 1.19$ & $10.06 \pm 1.54$ & $<0.001^{*}$ \\
\hline PDW (fL) & $15.72 \pm 2.30$ & $17.00 \pm 1.78$ & $<0.001^{*}$ \\
\hline WBC counts $\left(\times 10^{9} / \mathrm{L}\right)$ & $6.77 \pm 1.91$ & $6.58 \pm 4.85$ & $0.001^{*}$ \\
\hline NEUT\% $(\%)$ & $57.15 \pm 22.41$ & $40.59 \pm 31.09$ & $<0.001^{*}$ \\
\hline $\mathrm{TC}(\mathrm{mmol} / \mathrm{L})$ & $4.34 \pm 1.07$ & $4.38 \pm 1.14$ & 0.685 \\
\hline Triglyceride (mmol/L) & $1.63 \pm 0.97$ & $1.64 \pm 1.11$ & 0.694 \\
\hline $\mathrm{HDL}-\mathrm{C}(\mathrm{mmol} / \mathrm{L})$ & $1.11 \pm 0.31$ & $1.26 \pm 0.32$ & $<0.001^{*}$ \\
\hline LDL-C (mmol/L) & $2.11 \pm 0.71$ & $2.06 \pm 0.75$ & 0.481 \\
\hline apoA1 (g/L) & $1.09 \pm 0.24$ & $1.20 \pm 0.24$ & $0.001^{*}$ \\
\hline apoB $(\mathrm{g} / \mathrm{L})$ & $1.23 \pm 3.73$ & $0.79 \pm 0.22$ & 0.191 \\
\hline BUN (mmol/L) & $7.31 \pm 3.80$ & $5.10 \pm 1.37$ & $<0.001^{*}$ \\
\hline Creatinine (umol/L) & $98.50 \pm 38.59$ & $59.67 \pm 11.50$ & $<0.001^{*}$ \\
\hline eGFR $\left(\mathrm{mL} / \mathrm{min} \cdot 1.73 \mathrm{~m}^{2}\right)$ & $66.14 \pm 16.01$ & $120.68 \pm 22.20$ & $<0.001^{*}$ \\
\hline TBIL (umol/L) & $20.29 \pm 16.50$ & $16.02 \pm 7.43$ & 0.130 \\
\hline Albumin (g/L) & $36.69 \pm 4.91$ & $39.43 \pm 5.21$ & $<0.001^{*}$ \\
\hline $\operatorname{LVEF}(\%)$ & $34.34 \pm 7.06$ & $40.05 \pm 4.58$ & $<0.001^{*}$ \\
\hline
\end{tabular}

patients (7.1\%) have NYHA classification of class IV. The distribution of NYHA classification shows significant difference between the patients with or without renal dysfunction. A more severe NYHA classification (class III and IV) is noticed in patients with renal dysfunction when compared with patients without renal dysfunction $(40.7 \%$ vs $13.0 \%, P<0.001)$. The incidences of hypertension and diabetes mellitus are significantly higher in patients with renal dysfunction than those in patients without renal dysfunction (both $P<0.05$ ). The age, plateletcrit, MPV, WBC counts, NEUT\%, BUN, creatinine and eGFR in patients with renal dysfunction are significantly higher than those in patients without renal dysfunction (all $P<0.05)$. The waist circumference, PDW, HDL-C, apoA1, albumin and LVEF in patients with renal dysfunction are significantly lower than those in patients without renal dysfunction (all $P<0.05)$. The BMI, smoking index, RBC counts, hemoglobin, platelet counts, TC, triglyceride, LDL-C, apoB and TBIL showed no significant difference between the patients with renal dysfunction and the patients without renal dysfunction.

The Pearson correlation analysis between eGFR and lipid, clinical, laboratory factors in heart failure patients are showed in Table 2. The waist circumference, platelet counts, PDW, HDL-C, apoA1, albumin and LVEF are positively correlated with eGFR (all $P<0.05$ ). Meanwhile, the age, MPV, NEUT\%, BUN, creatinine and TBIL are negatively correlated with eGFR (all $P<0.05$ ). The BMI, smoking index, RBC counts, hemoglobin, plateletcrit, TC, triglyceride, LDL-C and apo B show no correlation with eGFR. 


\section{Kidney Blood Pressure Research}

Since the HDL-C and apoA1 are the only two lipid indicators correlated with eGFR, we have built the Logistic regressions for renal dysfunction using HDL-C and apoA1 simultaneously. The Logistic regression analyses are showed in Table 3. In Table 3, we have enrolled all the factors significantly correlated with eGFR except creatinine, BUN, since the two renal function factors are highly correlated with eGFR. Meanwhile, we have also enrolled the significantly varied categorical factor sex, hypertension and diabetes mellitus in the Logistic regression, the NYHA classification is not in the regression since it is closely related with LVEF. After the adjustment of sex, hypertension, diabetes mellitus, age, waist circumference, platelet counts, MPV, PDW, NEUT\%, TBIL, albumin and LVEF, HDL-C is still significantly associated with renal dysfunction in hospitalized heart failure patients $(O R=0.119, P=0.003)$, the apoA1 is not significantly associated with renal dysfunction in hospitalized heart failure patients $(O R=0.204, P=0.235)$.

\section{Discussion}

Heart and kidney are tightly connected organs in heart failure. Previous studies have demonstrated high prevalence of renal dysfunction in heart failure patients [6-8]. A recent UK national study has documented the prevalence of CKD (eGFR<60 ml/ $\min \cdot 1.73 \mathrm{~m}^{2}$ ) in the HF community is $63 \%$ [5]. Whilst the high prevalence of CKD in the community HF population is consist with that in hospital [19] and other specialist care settings [20]. In this present study, 8 patients (2.4\%) has eGFR of $15-30 \mathrm{~mL} /$ $\min \cdot 1.73 \mathrm{~m}^{2}, 46$ patients $(13.7 \%)$ has eGFR of $30-59$ $\mathrm{mL} / \mathrm{min} \cdot 1.73 \mathrm{~m}^{2}, 128$ patients (38.1\%) has eGFR of $60-89 \mathrm{~mL} / \mathrm{min} \cdot 1.73 \mathrm{~m}^{2}, 154$ patients $(45.8 \%)$ has eGFR $\geq 90 \mathrm{~mL} / \mathrm{min} \cdot 1.73 \mathrm{~m}^{2}$. When compared with $63 \%$ in UK, the prevalence of CKD $(\mathrm{eGFR}<60 \mathrm{ml} /$

Table 3. Logistic regression analysis for renal dysfunction using lipid and confounding factors in heart failure patients. Note: CI, Confidence Interval; MPV, Mean Platelet Volume; PDW, Platelet Distribution Width; NEUT\%, Neutrophilic Granulocyte Percentage; HDL-C, High-Density LipoproteinCholesterol; apoA1, apolipoprotein A1; TBIL, Total Bilirubin; LVEF, Left Ventricular Ejection Fraction; * $\mathrm{P}<0.05$

\begin{tabular}{lccc}
\hline Factors & Odd ratios & $95 \%$ CI. & $P$ value \\
\hline Male & 0.082 & $0.026-0.257$ & $<0.001^{*}$ \\
Hypertension & 3.731 & $1.309-10.632$ & $0.014^{*}$ \\
Diabetes mellitus & 1.006 & $0.269-3758$ & 0.993 \\
Age & 1.006 & $0.962-1.053$ & 0.782 \\
Waist circumference & 0.969 & $0.915-1.026$ & 0.278 \\
Platelet counts & 1.003 & $0.994-1.011$ & 0.540 \\
MPV & 1.962 & $1.227-3.138$ & $0.005^{*}$ \\
PDW & 0.650 & $0.477-0.888$ & $0.007^{*}$ \\
NEUT\% & 0.989 & $0.941-1.040$ & 0.666 \\
HDL-C & 0.064 & $0.010-0.420$ & $0.004^{*}$ \\
apoA1 & 0.204 & $0.015-2.809$ & 0.235 \\
TBIL & 1.011 & $0.954-1.070$ & 0.715 \\
Albumin & 0.840 & $0.741-0.951$ & $0.006^{*}$ \\
LVEF & 0.942 & $0.897-0.989$ & $0.017^{*}$ \\
\hline
\end{tabular}

Table 2. Pearson correlation analysis between eGFR and lipid and other clinical and laboratory factors in heart failure patients. Note: eGFR, estimated glomerular filtration rate; BMI, Body Mass Index; RBC, Red Blood Cells; MPV, Mean Platelet Volume; PDW, Platelet Distribution Width; WBC, White Blood Cells; NEUT\%, neutrophilic granulocyte percentage; TC, Total Cholesterol; HDL-C, High-Density Lipoprotein-Cholesterol; LDL-C, Low-Density LipoproteinCholesterol; apoA1, apolipoprotein A1; apoB, apolipoprotein B; BUN, Urea Nitrogen; TBIL, Total Bilirubin; LVEF, Left Ventricular Ejection Fraction; * $\mathrm{P}<0.05$

\begin{tabular}{lcc}
\hline Factors & $r$ & $P$ value \\
\hline Age & -0.212 & $<0.001^{*}$ \\
BMI & 0.082 & 0.132 \\
Waist circumference & 0.177 & $0.001^{*}$ \\
Smoking index & -0.050 & 0.365 \\
RBC counts & -0.106 & 0.056 \\
Hemoglobin & -0.104 & 0.059 \\
Platelet counts & 0.130 & $0.019^{*}$ \\
Plateletcrit & -0.005 & 0.933 \\
MPV & -0.235 & $<0.001^{*}$ \\
PDW & 0.243 & $<0.001^{*}$ \\
WBC counts & -0.040 & 0.477 \\
NEUT\% & -0.266 & $<0.001^{*}$ \\
TC & 0.054 & 0.338 \\
Triglyceride & -0.029 & 0.600 \\
HDL-C & 0.249 & $<0.001^{*}$ \\
LDL-C & -0.015 & 0.793 \\
apoA1 & 0.262 & $<0.001^{*}$ \\
apoB & -0.065 & 0.243 \\
BUN & -0.507 & $<0.001^{*}$ \\
Creatinine & -0.744 & $<0.001^{*}$ \\
TBIL & -0.127 & $0.022^{*}$ \\
Albumin & 0.237 & $<0.001^{*}$ \\
LVEF & 0.314 & $<0.001^{*}$ \\
\hline
\end{tabular}




\section{Kidney Blood Pressure Research}

Kidney Blood Press Res 2019;44:52-61

\begin{tabular}{l|l}
\hline DOI: 10.1159/000498834 & (c) 2019 The Author(s). Published by S. Karger AG, Base
\end{tabular}

Published online: 22 February 2019 www.karger.com/kbr

Zhang et al.: Lipid and Renal Dysfunction

$\min / 1.73 \mathrm{~m}^{2}$ ) is $16.1 \%$ in our population. The reasons for the difference may come from the difference in EF and NYHA classification since the previous UK study lacked data of ejection fraction or NYHA classification. Our results were consist with the results from dalOUTCOMES study, it reported that $11 \%$ of all participants had an eGFR $<60 \mathrm{~mL} / \mathrm{min} \cdot 1.73$ $\mathrm{m}^{2}$, indicating that CKD is highly prevalent in patients with CAD patients, especially in heart failure patients [21]. Löfman I et al. [22] reported increasing mortality with decreasing kidney function regardless of age, presence of diabetes, NYHA class, duration of heart failure and haemoglobin levels in 47, 716 Swedish HF patients. It was also documented that when the kidney damage appeared, mortality and morbidity significantly increased in heart failure patients $[23,24]$, an $11 \%$ increase in hospitalization and $17 \%$ in mortality were noticed in the CKD patients.

The mechanisms of renal dysfunction in heart failure patients can be complicated and multifactorial, the reduced renal perfusion and venous congestion may come as the most important elements [25]. A variety of other mechanisms such as inflammatory and cellular immune-mediated mechanisms; stress-mediated and neuro-hormonal responses; metabolic and nutritional alteration including bone and mineral disorders, altered haemodynamic and acid-base or fluid status; development of anaemia and intrinsic tubular damage also play important roles in the process [26-30]. Among the various reasons, dyslipidemia may also be one of them for renal dysfunction in heart failure patients [31]. Dyslipidemia is often characterized with elevated plasma triglycerides and LDL-C and reduced HDL-C concentrations [32]. In epidemiologic studies based on humans, the presence of dyslipidemia is significantly associated with a higher risk of suffering form renal dysfunction in the CKD population [33-35]. The studies based on animals have shown that the development and progression of kidney damage is associated with increased glomerulosclerosis and tubulointerstitial damage caused by hyperlipidemia [36].

This present study reveal that after adjustments of confounding factors, HDL-C is still associated with renal dysfunction in heart failure patients, but the LDL-C, TG, TC, apoA1 and apoB show no association with renal dysfunction. Whether HDL-C levels can be used as predictors of kidney function declination is still controversial in previous cohort studies. Some studies showed that low HDL-C levels were associated with a faster rate of progression of kidney disease [37]. One recent randomization analysis demonstrated that genetically higher HDL cholesterol concentration was associated with better kidney function based on large samples form the largest lipid and CKD cohorts [11]. Visconti L et al. [38] also reported lipid disorders in CKD was characterized by reduced HDL-C, high triglycerides and normal or slightly reduced LDL-C level. The mechanism for the association is not entirely clear, previous studies showed that the HDL-C had the antioxidant, anti-inflammatory and antithrombotic functions, which would reduce atherosclerosis in renal arteries and other arteries, it may serve as the protector of the renal functions [39]. Second, the decreased apoA1 and lecithin cholesterol acyltransferase deficiency were often documented in patients with kidney dysfunction, they could lead to lower plasma HDL-C [40, 41]. On the contrary, in a large cohort of 3939 patients with CKD, the total cholesterol, triglycerides, VLDL-C, LDL-C, HDL-C, apoA1, and apoB were not independently associated with progression of kidney disease [42]. The reason may be that the HDL particle is highly complicated and over 80 proteins and several hundred lipids are carried within it. Simple cholesterol measurement might not allow us to obtain the biologic functions of the specific HDL particles $[39,40]$. Therefore, functional studies of each HDL component in the cholesterol efflux capacity and the reverse cholesterol transport, would be needed in the future [43].

In this present study, we also found that some other confounding factors were also associated with renal function after adjustments in heart failure patients. The albumin, LVEF and PDW showed the protective effects on renal function and the female, hypertension and MPV showed the opposite effects on renal function. It is easy to understand that the improve of heart function (LVEF) [44] and nutrition status (albumin) [45] may lead to better kidney perfusion and less kidney damage, which could result in better renal function. 


\section{Kidney \\ Blood Pressure Research}

Meanwhile, female sex [46] and hypertension [47] were traditional risk factors responsible for the deterioration of renal function. Interestingly, MPV was found to be a risk factor for renal function with $O R=1.992(P=0.005)$. Some studies have documented the association between MPV and inflammation [48]. The mechanism may be as follows, the heart failure process is also a process of inflammatory, increased inflammatory mediators may affect MPV, then it might induce larger and more reactive platelets [49]. Since the bone marrow might be exposed to chronic inflammation caused by heart failure for a period of long time, the inflammatory mediators would have enough time to make changes on MPV [50]. The documented association of PDW and renal function is rare, interestingly, PDW has been added as a novel prognostic marker of cardiovascular death in some researches [51]. Further study may focus on the mechanism of association of PDW and renal function in heart failure patients.

The strength of the study is that the association between the lipids profile and renal function is first established in specific population, the heart failure patients. The population has unique feature of lipids profile and renal function. The association between the HDL-C and eGFR could be used as evidence for modulation of HDL-C for better kidney function in heart failure patients. The study has also several limitations, the cross-section study could not determine the causal relationship between HDL-C declination and renal dysfunction. Second, the urine samples were not collected in this study, therefore, the incidence of renal dysfunction may be under-estimated.

\section{Conclusion}

In conclusion, in this cross-sectional study based on patients with heart failure, HDL-C is still significantly associated with renal dysfunction in hospitalized heart failure patients after the adjustment of sex, hypertension, diabetes mellitus, age, waist circumference, platelet counts, MPV, PDW, NEUT\%, TBIL, albumin and LVEF. Further researches are needed to determine the subtype of HDL-C associated with renal dysfunction and clarify whether mandatory elevation of the specific subtype of HDL-C may improve the kidney function in heart failure patients.

\section{Abbreviations}

apoA1 (apolipoprotein A1); apoB (apolipoprotein B); BMI (body mass index); CI (confidence interval); BUN (urea nitrogen); eGFR (estimated glomerular filtration rate); CKD (chronic kidney disease); HDL-C (high density lipoprotein-cholesterol); HF (heart failure); LDL-C (low-density lipoprotein-cholesterol); LVEF (left ventricular ejection fraction); MPV (mean platelet volume); NEUT\%, neutrophilic (granulocyte percentage); NYHA (New York Heart Association); PDW (platelet distribution width); RBC (red blood cells); SD (standard deviation); TBIL (total bilirubin); TC (total cholesterol); WBC (white blood cells).

\section{Acknowledgements}

This paper was funded by National Natural Science Funds of China (Grant No. 81500308), China Postdoctoral Science Foundation (Nos. 2017M623371) and Basic Research Program of Natural Science of Shaanxi Province (2017JM8117). 


\section{Kidney \\ Blood Pressure Research}

\begin{tabular}{l}
\hline Kidney Blood Press Res 2019;44:52-61 \\
\begin{tabular}{l|l} 
DOI: 10.1159/000498834 & $\begin{array}{l}\text { ○ } 2019 \text { The Author(s). Published by S. Karger AG, Basel } \\
\text { www.karger.com/kbr }\end{array}$ \\
Published online: 22 February 2019
\end{tabular} \\
\hline
\end{tabular}

Zhang et al.: Lipid and Renal Dysfunction

\section{Disclosure Statement}

The authors declare that they have no conflicts of interest.

\section{References}

1 Ter Maaten JM, Damman K, Verhaar MC, Paulus WJ, Duncker DJ, Cheng C, van Heerebeek L, Hillege HL, Lam CS, Navis G, Voors AA: Connecting heart failure with preserved ejection fraction and renal dysfunction: the role of endothelial dysfunction and inflammation. Eur J Heart Fail 2016;18:588-598.

$\checkmark 2$ Damman K, Valente MA, Voors AA, O'Connor CM, van Veldhuisen DJ, Hillege HL: Renal impairment, worsening renal function, and outcome in patients with heart failure: an updated meta-analysis. Eur Heart J 2014;35:455-469.

3 Damman K, Testani JM: The kidney in heart failure: an update. Eur Heart J 2015;36:1437-1444.

4 Cole RT, Masoumi A, Triposkiadis F, Giamouzis G, Georgiopoulou V, Kalogeropoulos A, Butler J: Renal dysfunction in heart failure. Med Clin North Am 2012;96:955-974.

5 Lawson CA, Testani JM, Mamas M, Damman K, Jones PW, Teece L, Kadam UT: Chronic kidney disease, worsening renal function and outcomes in a heart failure community setting: A UK national study. Int J Cardiol 2018;267:120-127.

6 Mullens W, Abrahams Z, Francis GS, Sokos G, Taylor DO, Starling RC, Young JB, Tang WH: Importance of venous congestion for worsening of renal function in advanced decompensated heart failure. J Am Coll Cardiol 2009;53:589-596.

7 Greene SJ, Butler J, Albert NM, DeVore AD, Sharma PP, Duffy CI, Hill CL, McCague K, Mi X, Patterson JH, Spertus JA, Thomas L, Williams FB, Hernandez AF, Fonarow GC: Medical Therapy for Heart Failure With Reduced Ejection Fraction: The CHAMP-HF Registry. J Am Coll Cardiol 2018;72:351-366.

8 Dupont M, Mullens W, Finucan M, Taylor DO, Starling RC, Tang WH: Determinants of dynamic changes in serum creatinine in acute decompensated heart failure: the importance of blood pressure reduction during treatment. Eur J Heart Fail 2013;15:433-440.

-9 Gergei I, Krämer BK, Scharnagl H, Stojakovic T, März W. Renal function, N-terminal Pro-B-Type natriuretic peptide, propeptide big-endothelin and patients with heart failure and preserved ejection fraction. Peptides 2018; DOI:10.101/j.peptides.2018.04.003.

-10 Jang SY, Chae SC, Bae MH, Lee JH, Yang DH, Park HS, Cho Y, Cho HJ, Lee HY, Oh BH, Choi JO, Jeon ES, Kim MS, Lee SE, Kim JJ, Hwang KK, Cho MC, Baek SH, Kang SM, Choi DJ, et al.: Effect of renin-angiotensin system blockade in patients with severe renal insufficiency and heart failure. Int J Cardiol 2018;266:180-186.

11 Lanktree MB, Thériault S, Walsh M, Paré G: HDL Cholesterol, LDL Cholesterol, and Triglycerides as Risk Factors for CKD: A Mendelian Randomization Study. Am J Kidney Dis 2018;71:166-172.

12 Hunt SA, Abraham WT, Chin MH, Feldman AM, Francis GS, Ganiats TG, Jessup M, Konstam MA, Mancini DM, Michl K, Oates JA, Rahko PS, Silver MA, Stevenson LW, Yancy CW, Antman EM, Smith SC Jr, Adams CD, Anderson JL, Faxon DP, et al.: ACC/AHA 2005 Guideline Update for the Diagnosis and Management of Chronic Heart Failure in the Adult: a report of the American College of Cardiology/American Heart Association Task Force on Practice Guidelines (Writing Committee to Update the 2001 Guidelines for the Evaluation and Management of Heart Failure): developed in collaboration with the American College of Chest Physicians and the International Society for Heart and Lung Transplantation: endorsed by the Heart Rhythm Society. Circulation 2005;112:e154-235.

13 Pan S, Liu ZW, Lv Y, Song WQ, Ma X, Guan GC, Zhang Y, Zhu SM, Liu FQ, Liu B, Tang ZG, Wang JK: Association between neutrophilic granulocyte percentage and depression in hospitalized patients with heart failure. BMC Psychiatry 2016;16:446.

14 Matsushita K, Kwak L, Sang Y, Ballew SH, Skali H, Shah AM, Coresh J, Solomon S: Kidney Disease Measures and Left Ventricular Structure and Function: The Atherosclerosis Risk in Communities Study. J Am Heart Assoc 2017;6:e006259.

15 Zhao B, Han H, Yang X, Wang R: Comparison of four eGFR equations in assessing complications associated with chronic loss of kidney function: A cross-sectional study in a Chinese population. Clin Nephrol 2018;90:246-254. 


\section{Kidney \\ Blood Pressure Research}

16 Pan S, Yu ZX, Ma YT, Liu F, Yang YN, Ma X, Fu ZY, Li XM, Xie X, Chen Y, Chen B, He CH: Appropriate body mass index and waist circumference cutoffs for categorization of overweight and central adiposity among Uighur adults in Xinjiang. PLoS One 2013;8:e80185.

17 Pan S, Liu ZW, Shi S, Ma X, Song WQ, Guan GC, Zhang Y, Zhu SM, Liu FQ, Liu B, Tang ZG, Wang JK, Lv Y: Hamilton rating scale for depression-24 (HAM-D24) as a novel predictor for diabetic microvascular complications in type 2 diabetes mellitus patients. Psychiatry Res 2017;258:177-183.

18 Pan S, Guan GC, Lv Y, Liu ZW, Liu FQ, Zhang Y, Zhu SM, Zhang RH, Zhao N, Shi S, Nakayama T, Wang JK: G-T haplotype established by rs3785889-rs16941382 in GOSR2 gene is associated with coronary artery disease in Chinese Han population. Oncotarget 2017;8:82165-82173.

19 Pimentel R, Couto M, Laszczyńska 0, Friões F, Bettencourt P, Azevedo A: Prognostic value of worsening renal function in outpatients with chronic heart failure. Eur J Intern Med 2014;25:662-668.

20 Go AS, Yang J, Ackerson LM, Lepper K, Robbins S, Massie BM, Shlipak MG: Hemoglobin level, chronic kidney disease, and the risks of death and hospitalization in adults with chronic heart failure: the Anemia in Chronic Heart Failure: Outcomes and Resource Utilization (ANCHOR) Study. Circulation 2006;113:27132723.

21 Shlipak MG, Simon JA, Grady D, Lin F, Wenger NK, Furberg CD: Renal insufficiency and cardiovascular events in postmenopausal women with coronary heart disease. J Am Coll Cardiol 2001;38:705-711.

22 Löfman I, Szummer K, Hagerman I, Dahlström U, Lund LH, Jernberg T: Prevalence and prognostic impact of kidney disease on heart failure patients. Open Heart 2016;3:e000324.

-23 Josa-Laorden C, Sola A, Giménez-López I, Rubio-Gracia J, Garcés-Horna V, Pérez-Calvo JI: Prognostic value of the urea: creatinine ratio in decompensated heart failure and its relationship with acute kidney damage. Rev Clin Esp 2018;218:232-240.

-24 Untersteller K, Seiler-Mußler S, Mallamaci F, Fliser D, London GM, Zoccali C, Heine GH: Validation of echocardiographic criteria for the clinical diagnosis of heart failure in chronic kidney disease. Nephrol Dial Transplant 2017; DOI:10.1093/ndt/gfx197.

-25 Nohria A, Hasselblad V, Stebbins A, Pauly DF, Fonarow GC, Shah M, Yancy CW, Califf RM, Stevenson LW, Hill JA: Cardiorenal interactions: insights from the ESCAPE trial. J Am Coll Cardiol 2008;51:1268-1274.

26 Metra M, Cotter G, Gheorghiade M, Dei Cas L, Voors AA: The role of the kidney in heart failure. Eur Heart J 2012;33:2135-2142.

27 Colombo PC, Ganda A, Lin J, Onat D, Harxhi A, Iyasere JE, Uriel N, Cotter G: Inflammatory activation: cardiac, renal, and cardio-renal interactions in patients with the cardiorenal syndrome. Heart Fail Rev 2012;17:177-190.

28 Shrestha K, Shao Z, Singh D, Dupont M, Tang WH: Relation of systemic and urinary neutrophil gelatinaseassociated lipocalin levels to different aspects of impaired renal function in patients with acute decompensated heart failure. Am J Cardiol 2012;110:1329-1335.

-29 Collins SP, Hart KW, Lindsell CJ, Fermann GJ, Weintraub NL, Miller KF, Roll SN, Sperling MI, Sawyer DB, Storrow AB: Elevated urinary neutrophil gelatinase-associated lipocalcin after acute heart failure treatment is associated with worsening renal function and adverse events. Eur J Heart Fail 2012;14:10201029.

-30 Schefold JC, Filippatos G, Hasenfuss G, Anker SD, von Haehling S: Heart failure and kidney dysfunction: epidemiology, mechanisms and management. Nat Rev Nephrol 2016;12:610-623.

-31 Kaysen GA: New insights into lipid metabolism in chronic kidney disease. J Ren Nutr 2011;21:120-123.

-32 Vaziri ND: Lipotoxicity and impaired high density lipoprotein-mediated reverse cholesterol transport in chronic kidney disease. J Ren Nutr 2010;20:S35-43.

33 Iseki K: Epidemiology of dyslipidemia in chronic kidney disease. Clin Exp Nephrol 2014;18:185-188.

-34 Mikolasevic I, Žutelija M, Mavrinac V, Orlic L: Dyslipidemia in patients with chronic kidney disease: etiology and management. Int J Nephrol Renovasc Dis 2017;10:35-45.

35 Pandya V, Rao A, Chaudhary K: Lipid abnormalities in kidney disease and management strategies. World J Nephrol 2015;4:83-91.

-36 Asahina M, Shimizu F, Ohta M, Takeyama M, Tozawa R: Human apolipoprotein B transgenic SHR/NDmcr-cp rats show exacerbated kidney dysfunction. Exp Anim 2015;64:313-321.

-37 Li L, Astor BC, Lewis J, Hu B, Appel LJ, Lipkowitz MS, Toto RD, Wang X, Wright JT Jr, Greene TH: Longitudinal progression trajectory of GFR among patients with CKD. Am J Kidney Dis 2012;59:504-512. 


\section{Kidney \\ Bloód Pressure Research}

Kidney Blood Press Res 2019;44:52-61
\begin{tabular}{l|l}
\hline DOl: 10.1159/000498834 & $\begin{array}{l}\text { c } 2019 \text { The Author(s). Published by S. Karger AG, Basel } \\
\text { www.karger.com/kbr }\end{array}$ \\
\hline Published onlIne: 22 February 2019
\end{tabular}

Zhang et al.: Lipid and Renal Dysfunction

38 Visconti L, Benvenga S, Lacquaniti A, Cernaro V, Bruzzese A, Conti G, Buemi M, Santoro D: Lipid disorders in patients with renal failure: Role in cardiovascular events and progression of chronic kidney disease. J Clin Transl Endocrinol 2016;6:8-14.

39 Moradi H, Pahl MV, Elahimehr R, Vaziri ND: Impaired antioxidant activity of high-density lipoprotein in chronic kidney disease. Transl Res 2009;153:77-85.

40 Zewinger S, Speer T, Kleber ME, Scharnagl H, Woitas R, Lepper PM, Pfahler K, Seiler S, Heine GH, März W, Silbernagel G, Fliser D: HDL cholesterol is not associated with lower mortality in patients with kidney dysfunction. J Am Soc Nephrol 2014;25:1073-1082.

41 Hager MR, Narla AD, Tannock LR: Dyslipidemia in patients with chronic kidney disease. Rev Endocr Metab Disord 2017;18:29-40.

42 Rahman M, Yang W, Akkina S, Alper A, Anderson AH, Appel LJ, He J, Raj DS, Schelling J, Strauss L, Teal V, Rader DJ: Relation of serum lipids and lipoproteins with progression of CKD: The CRIC study. Clin J Am Soc Nephrol 2014;9:1190-1198.

43 Kronenberg F: HDL in CKD-The Devil Is in the Detail. J Am Soc Nephrol 2018;29:1356-1371.

44 Lim WY, Ahsan S, Papageorgiou N: Heart and kidney failure: Two organs, two disease states? Int J Cardiol 2018;266:193-194.

45 Thongprayoon C, Cheungpasitporn W, Mao MA, Sakhuja A, Kashani K: U-shape association of serum albumin level and acute kidney injury risk in hospitalized patients. PLoS One 2018;13:e0199153.

46 Li J, Li Y, Xu B, Jia G, Guo T, Wang D, Xu K, Deng J, Han Y: Short-term rosuvastatin therapy prevents contrastinduced acute kidney injury in female patients with diabetes and chronic kidney disease: a subgroup analysis of the TRACK-D study. J Thorac Dis 2016;8:1000-1006.

47 Johnson RJ, Bakris GL, Borghi C, Chonchol MB, Feldman D, Lanaspa MA, Merriman TR, Moe OW, Mount DB, Sanchez Lozada LG, Stahl E, Weiner DE, Chertow GM: Hyperuricemia, Acute and Chronic Kidney Disease, Hypertension, and Cardiovascular Disease: Report of a Scientific Workshop Organized by the National Kidney Foundation. Am J Kidney Dis 2018;71:851-865.

48 Yilmaz G, Sevinc C, Ustundag S, Yavuz YC, Hacıbekiroglu T, Hatipoglu E, Baysal M: The relationship between mean platelet volume and neutrophil/lymphocyte ratio with inflammation and proteinuria in chronic kidney disease. Saudi J Kidney Dis Transpl 2017;28:90-94.

49 Gasparyan AY, Ayvazyan L, Mikhailidis DP, Kitas GD: Mean platelet volume: a link between thrombosis and inflammation? Curr Pharm Des 2011;17:47-58.

50 Chu SG, Becker RC, Berger PB, Bhatt DL, Eikelboom JW, Konkle B, Mohler ER, Reilly MP, Berger JS: Mean platelet volume as a predictor of cardiovascular risk: a systematic review and meta-analysis. J Thromb Haemost 2010;8:148-156.

51 Bekler A, Tenekecioğlu E, Erbağ G, Temiz A, Altun B, Barutçu A, Gazi E, Güneş F, Yılmaz M: Relationship between red cell distribution width and long-term mortality in patients with non-ST elevation acute coronary syndrome. Anatol J Cardiol 2015;15:634-639. 